\title{
Determination of obstructive sleep apnea through the epworth test and cephalometry
}

\begin{abstract}
The Obstructive Sleep Apnea Syndrome (OSAS) is a respiratory disorder during sleep characterized by a partial (Hypopnea), prolonged or intermittent obstruction (Apnea), as a consequence of an anatomical-functional alteration of the upper airway (VAS).

Interrupts normal ventilation during sleep: The importance of making an early diagnosis allows us to administer an adequate therapy and in this way modify the physiopathological mechanisms that alter the architecture of sleep and cardiopulmonary function.

Objective: This study aims to determine AOS through the Epworth test and cephalometry.

Methods: This is a cross-sectional descriptive observational study. The reference population was patients between 19 and 28 years of age attending the dental school of Rio Blanco Ver. The sample consisted of 40 patients (20 women and 20 men). A questionnaire (Epworth Test) was applied to identify the high suspicion of sleep disorder considering only those that had a result equal to or greater than 9 in the Test and lateral skull radiographs were taken. CruVariables were determined as: Facial axis, Mandibular position (FH-Na, Pog), Facial height (ENA-Xi), Mandibular length (Xi-Pog), Skeletal class (Plane AB of Downs, A, BN, Pg), Spradley Line (Upper Lip, Lower Lip and Pg) and Mc-Namara Airway (superior and posterior pharyngeal space).
\end{abstract}

Results: It was found that Skeletal Class II, Mandibular Retrusion, the Spradley line in relation to Pogonion, and the upper airway are directly related to the reduction of VAS, which in turn will trigger an important problem such as OSA.

Conclusion: The Epworth test showed significant importance as part of the diagnosis of OSA. The cephalometry is a useful to determine the values that indicate a high suspicion of OSA and that in turn confirm the presence or absence of it.

Keywords: sleep and cardiopulmonary function, pharyngeal space, statistical difference, tissue restoration, energy, cerebral thermoregulation, cerebral detoxification, memory, airway resistance syndrome, respiration, brain, sleep
Volume 10 Issue 4 - 2019

\author{
Cruz-Vargas Lizbet Adriana, Martínez-Reyes \\ María Guadalupe, González-Ramírez Alejandro \\ de Jesús, Cerda-Cristerna Bernardino Isaac, \\ Galindo-Reyes Lilia Edith, Suárez-Franco José \\ Luis \\ Faculty of Dentistry, Veracruzana University, Mexico
}

Correspondence: Suárez-Franco José Luis, Faculty of Dentistry of the Veracruzana University, Abasolo S/N, Tenango, Rio Blanco, Veracruz. C.P.94730, Mexico, Email jsuarez@uv.mx

Received: July 24, 2019 | Published: August 09, 2019
Abbreviations: ARS, respiratory sleep disorders; OSA, obstructive sleep apnea; VAS, visual analogue scale

\section{Introduction}

Sleep is a brain function. During sleep, control of respiration goes from being a semi-voluntary act to becoming a self-regulatory activity of highest biological priority. There are diverse physiological functions that the dream favors or allows and that are modified or suppressed after their deprivation as it is the conservation of energy; cerebral thermoregulation; cerebral detoxification; tissue restoration, memory and apprentice. ${ }^{1,2}$

Respiratory sleep disorders (ARS) are of two types: nonobstructive and obstructive. The former are usually of neurological origin and the latter are part of a group of disorders that comprise a wide spectrum of pathologies, among which is simple snoring, the increased airway resistance syndrome 7 (SRAVAS) and the syndrome of Obstructive sleep apnea (OSA). ${ }^{3,4}$

OSAS is characterized by the presence of recurrent episodes of collapse, total or partial, of the upper airway (VAS) during sleep. This manifests itself in a reduction (Hypopnea) or complete cessation (Apnea) of air flow despite inspiratory efforts. Buccal breathing is a syndrome that can be etiologically diagnosed by obstructive causes of VAS, by habits and by anatomy.
Obstructive sleep apnea (OSA) is therefore defined as intermittent and cyclical intermittent cessation of airflow in the mouth and nose during sleep. It is the alteration of breathing that has been most frequently described in the literature and is increasingly recognized as a serious public health problem. ${ }^{7,8}$

Recent studies have shown that not diagnosing and treating patients with OSAS either by obstruction or by habit, produces serious alterations in the stomatognathic system that affect both aesthetics and function. This disorder also has a negative impact on job performance and safety and is implicated in a considerable proportion of car accidents. ${ }^{9-11}$

There are several studies carried out to date that validate the cephalometric method as a coadjuvant for the obstructive problems of the VAS. This research aims to diagnose obstructive sleep apnea to students of the Faculty of Dentistry of Rio Blanco Ver., Through the Epworth test and cephalometry and to highlight the main factors associated with its etiology.

\section{Materials and methods}

This study is of a descriptive, cross-sectional observational type; the reference population was patients between 19 and 28 years of age who attend the Faculty of Dentistry of Río Blanco Ver. The sample consists of 40 patients: 20 men and 20 women. 
Initially, a questionnaire (Epworth Test) was applied to identify the high suspicion of sleep disorders. Subsequently, in patients who had a result equal to or greater than 9 in the Epworth test, lateral skull radiographs were taken with the patient in an upright position and with the Frankfort plane parallel to the floor in centric occlusion.
Variables were determined as: Facial axis (Ba-Na/Pt-Gn) Mandibular position (Ba-Na-Pg), Facial Height (ENA- Xi- Pg), Mandibular length (Xi-Pg), Skeletal Class with AB Plane Downs (Na$\mathrm{Pg} / \mathrm{AB}$ ), Spradley line (Upper lip, Lower lip and Pg) and Mc-Namara airway (superior and posterior pharyngeal space).

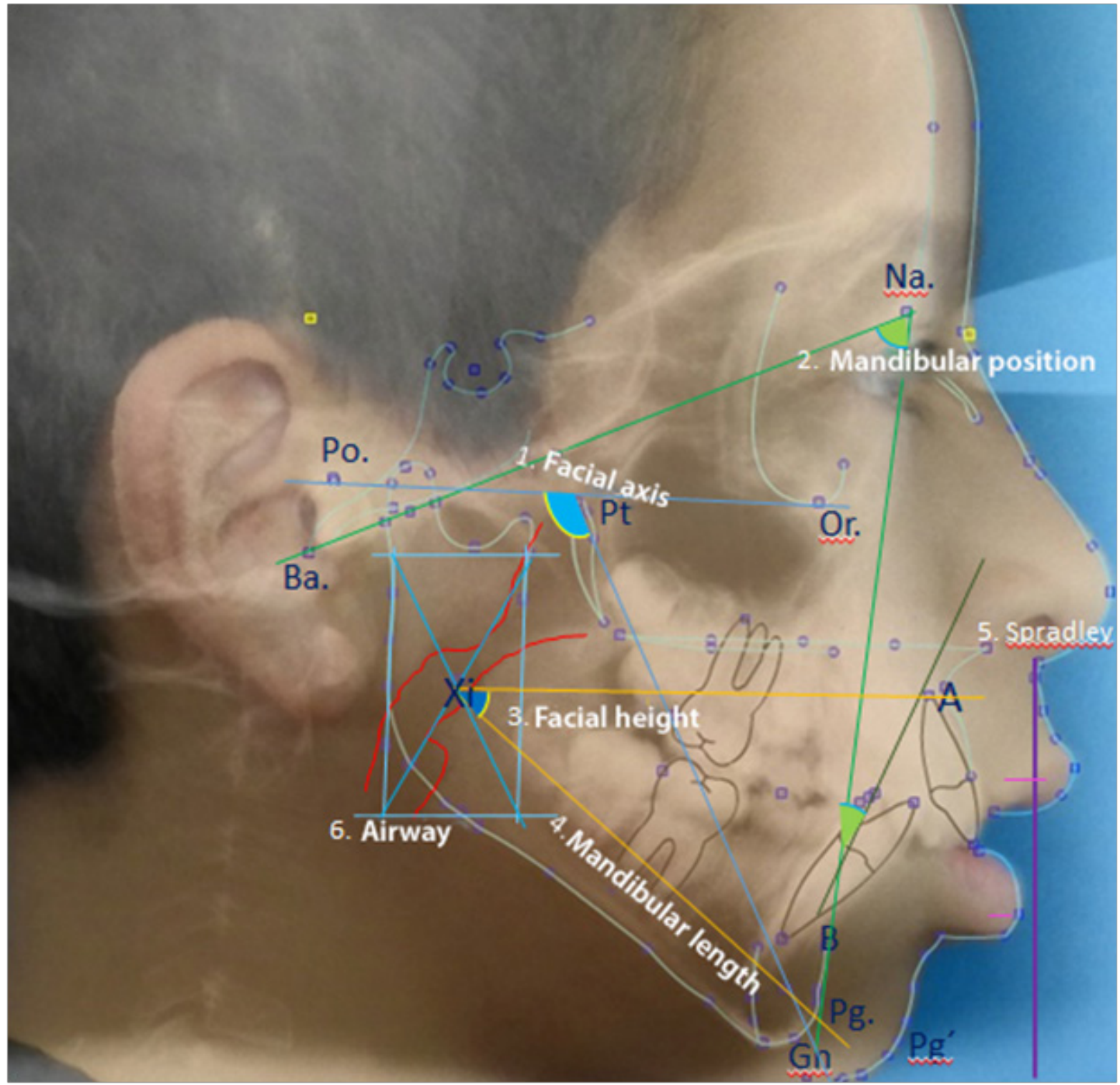

Figure I Variables.

Finally, the relationship between the survey filled out by the patient and obtaining the cephalometric measurements was confirmed.

\section{Statistical analysis}

According to the characteristics of the research, descriptive statistics were used, from which the information will be recorded in frequency tables.

\section{Results}

Statistically significant association was found with Apnea in Mandibular Position, Mandibular Length, Skeletal Class, Spradley in relation to Pogonion and Upper Airway. It was observed that skeletal class II presents a higher risk of suspicion of apnea than skeletal classes I. The micrognatic mandibular length presents more risk than a mandibular length within normal parameters. The decreased upper airway affects the passage of air flow. Finally, the male gender presented significant statistical difference compared to the female gender (Table 1).

According to the Epworth Test, 40 students between the ages of 19 and 28 were highly suspected of OSA, but compared to the cephalometric measurements obtained, 30 of them present problems with VAS Obstruction (Graph 1). 
Table I Factors associated with obstructive sleep apnea.

\begin{tabular}{|c|c|c|c|c|c|}
\hline \multirow[b]{2}{*}{ Variable } & \multirow[b]{2}{*}{ Characteristic } & \multicolumn{2}{|c|}{ Women } & \multicolumn{2}{|l|}{ Men } \\
\hline & & Patiens & Percentage & Patiens & Percentage \\
\hline \multirow[t]{3}{*}{ Facial axis } & Vertical growth & 4 & $20 \%$ & 6 & $30 \%$ \\
\hline & Normal growth & 9 & $45 \%$ & 11 & $55 \%$ \\
\hline & Horizontal growth & 7 & $35 \%$ & 3 & $15 \%$ \\
\hline \multirow[t]{3}{*}{ Mandibular position } & Vertical growth & 5 & $25 \%$ & 6 & $30 \%$ \\
\hline & Normal growth & 11 & $55 \%$ & 9 & $45 \%$ \\
\hline & Horizontal growth & 4 & $20 \%$ & 5 & $25 \%$ \\
\hline \multirow[t]{3}{*}{ Facial height } & Diminished & 3 & $15 \%$ & 4 & $20 \%$ \\
\hline & Adequate & 14 & $70 \%$ & 13 & $65 \%$ \\
\hline & Augmented & 3 & $15 \%$ & 3 & $15 \%$ \\
\hline \multirow[t]{3}{*}{ Mandibular length } & Diminished & 11 & $55 \%$ & 14 & $70 \%$ \\
\hline & Adequate & 8 & $40 \%$ & 5 & $25 \%$ \\
\hline & Augmented & I & $5 \% \%$ & 1 & $5 \%$ \\
\hline \multirow[t]{3}{*}{ Skeletal class } & I & 6 & $30 \%$ & 4 & $20 \%$ \\
\hline & II & 14 & $70 \%$ & 16 & $80 \%$ \\
\hline & III & 0 & $0 \%$ & 0 & $0 \%$ \\
\hline \multirow[t]{3}{*}{ Spradley Pg' } & Diminished & 2 & $10 \%$ & 5 & $25 \%$ \\
\hline & Adequate & 8 & $40 \%$ & 2 & $10 \%$ \\
\hline & Augmented & 10 & $50 \%$ & 13 & $65 \%$ \\
\hline \multirow[t]{3}{*}{ Superior airway } & Diminished & 13 & $65 \%$ & 17 & $85 \%$ \\
\hline & Adequate & 7 & $35 \%$ & 3 & $15 \%$ \\
\hline & Augmented & 0 & $0 \%$ & 0 & $0 \%$ \\
\hline \multirow[t]{3}{*}{ Rear airway } & Diminished & 2 & $10 \%$ & 6 & $30 \%$ \\
\hline & Adequate & 13 & $65 \%$ & 13 & $65 \%$ \\
\hline & Augmented & 5 & $25 \%$ & 1 & $5 \%$ \\
\hline
\end{tabular}

The percentage in terms of gender was $57 \%$ in men and $43 \%$ women (Graph 2).

\section{Graph I AOS Diagnostics.}

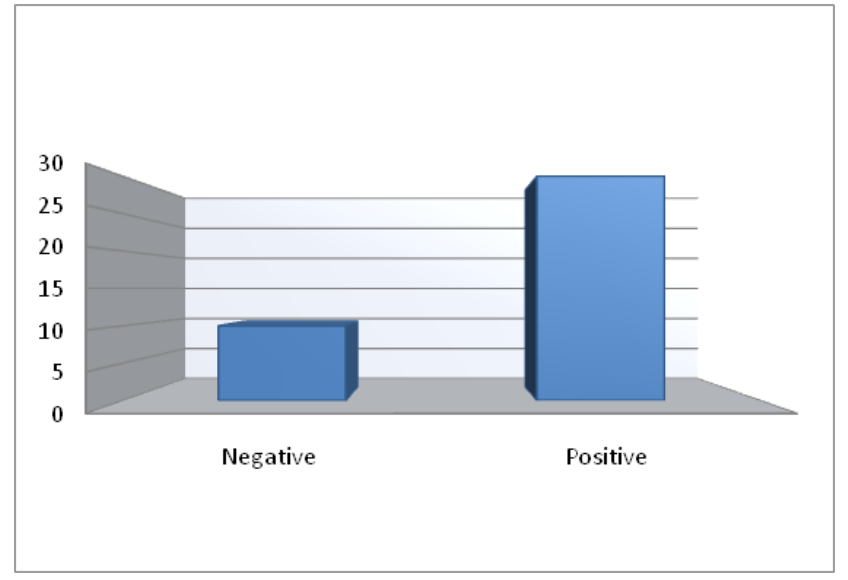

Citation: Adriana CVL, Guadalupe MRM, Jesús GRAD, et al. Determination of obstructive sleep apnea through the epworth test and cephalometry.J Dent Health Oral Disord Ther. 2019;10(4):25I-258. DOI: 10.15406/jdhodt.2019.10.00493 


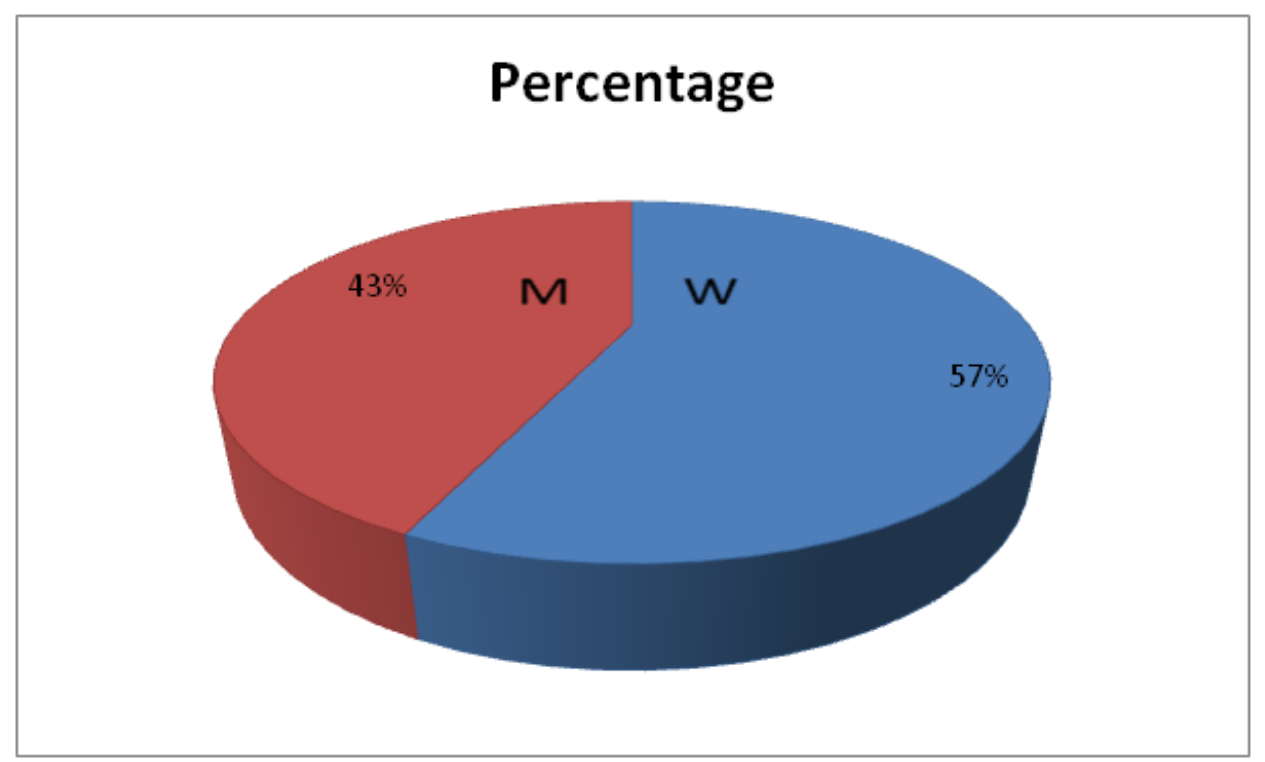

Graph 2 Percentage of gender women and men.

The Facial Axis of our population is in Norma. The male gender presented $55 \%$ compared to the female gender with $45 \%$. This indicates adequate growth (Graph 3).

The Facial Height of our population is in Norma. There was no significant difference in both genders (Graph 4).

The mandibular length that our population presents is mostly diminished. The male gender presented $70 \%$ compared to the female gender with $55 \%$. This decrease indicates a micrognatic jaw which is posteropositioned and influences the decrease in airway permeability (Graph 5).

The most prevalent skeletal class is Type II in both male and female gender with a percentage of 80 and $70 \%$ respectively. This class indicates a type of Vertical Growth, which leads the jaw to a post-position and thus a decrease in the airway (Graph 6).

The Spradley line in relation to Pogonion is shown increased in both genders. The male gender with $65 \%$ and the female gender with $50 \%$. This indicates a posteroposition of the mandibular body (Graph $7)$.

The upper Airway was found mostly diminished in the male gender with $85 \%$ compared to the female gender with $65 \%$. Which decreases hyperventilation of the upper airway. The posterior airway was found adequate in both genders, this can be associated with the type of facial growth that the patients presented (Graph 8).

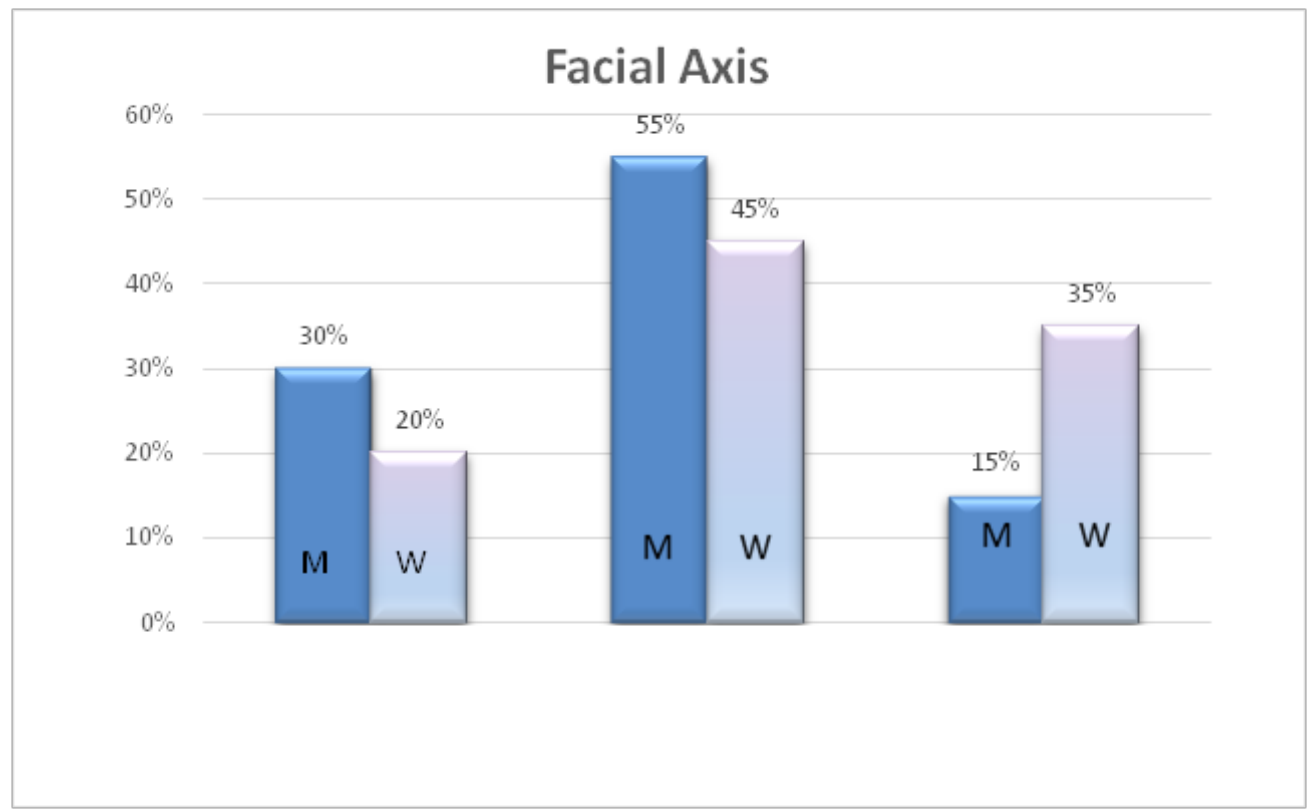

Graph 3 Percentage of women and men growth type. 


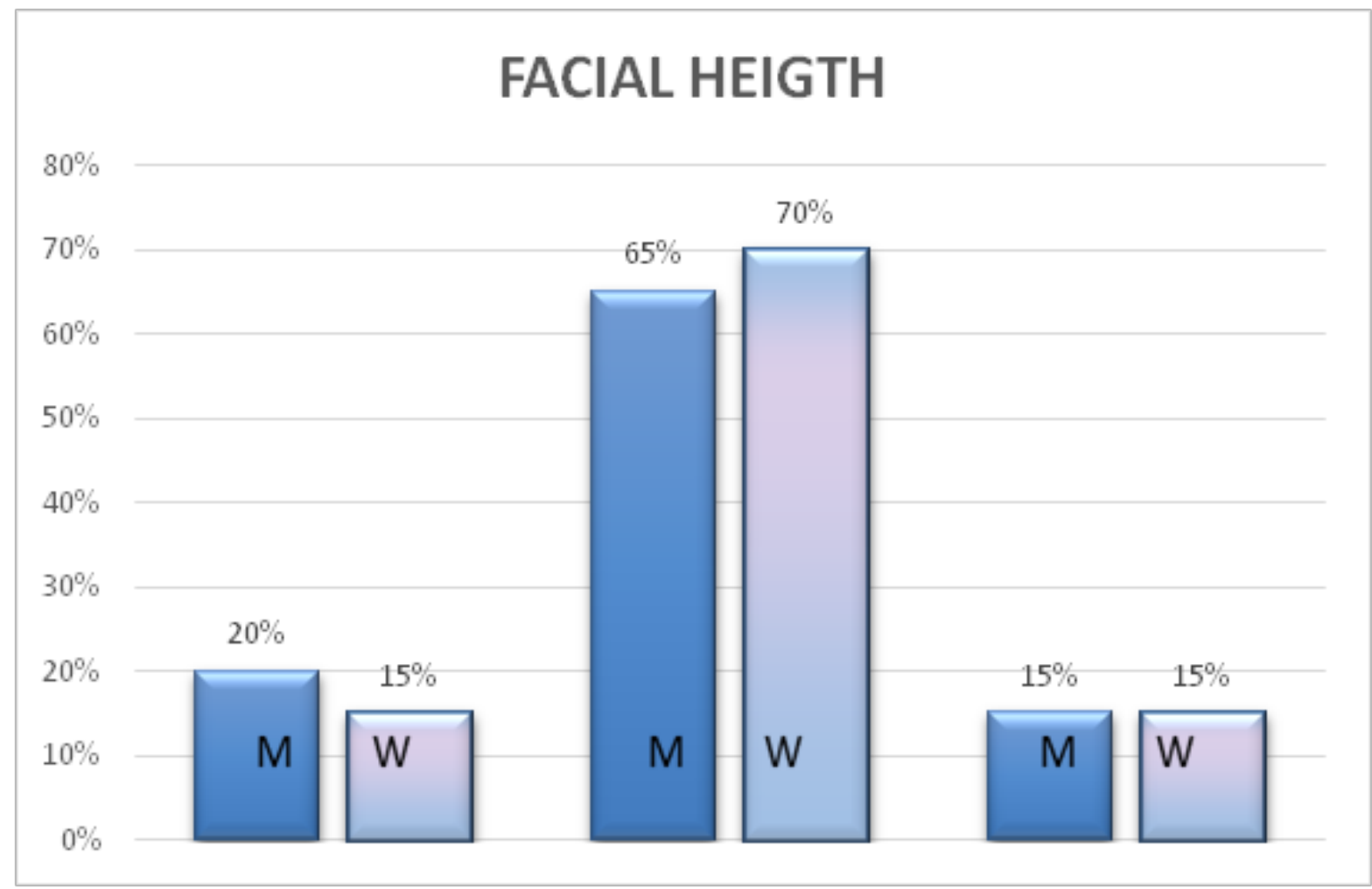

Graph 4 Percentage of facial height women and men

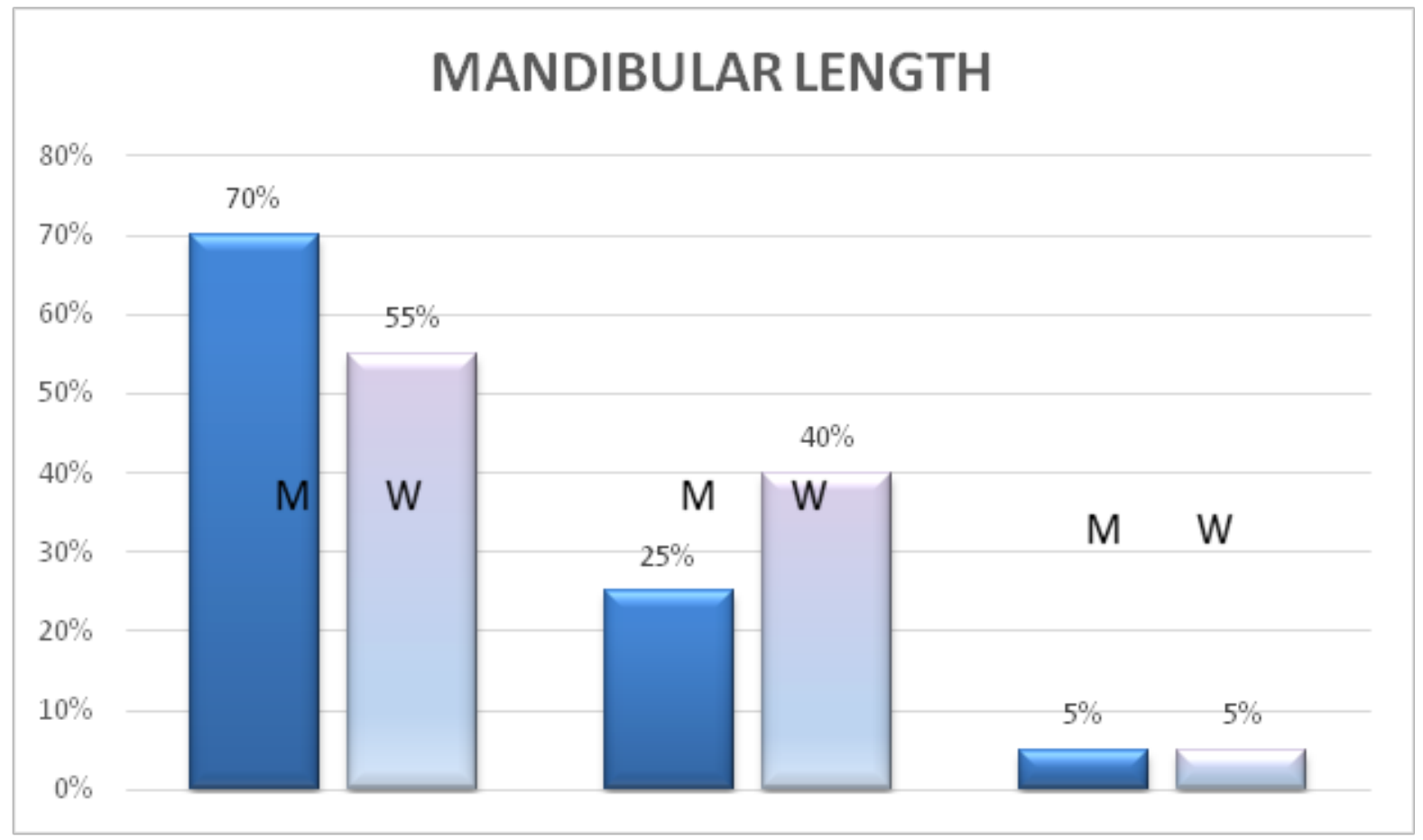

Graph 5 Percentage of mandibular length type women and men. 


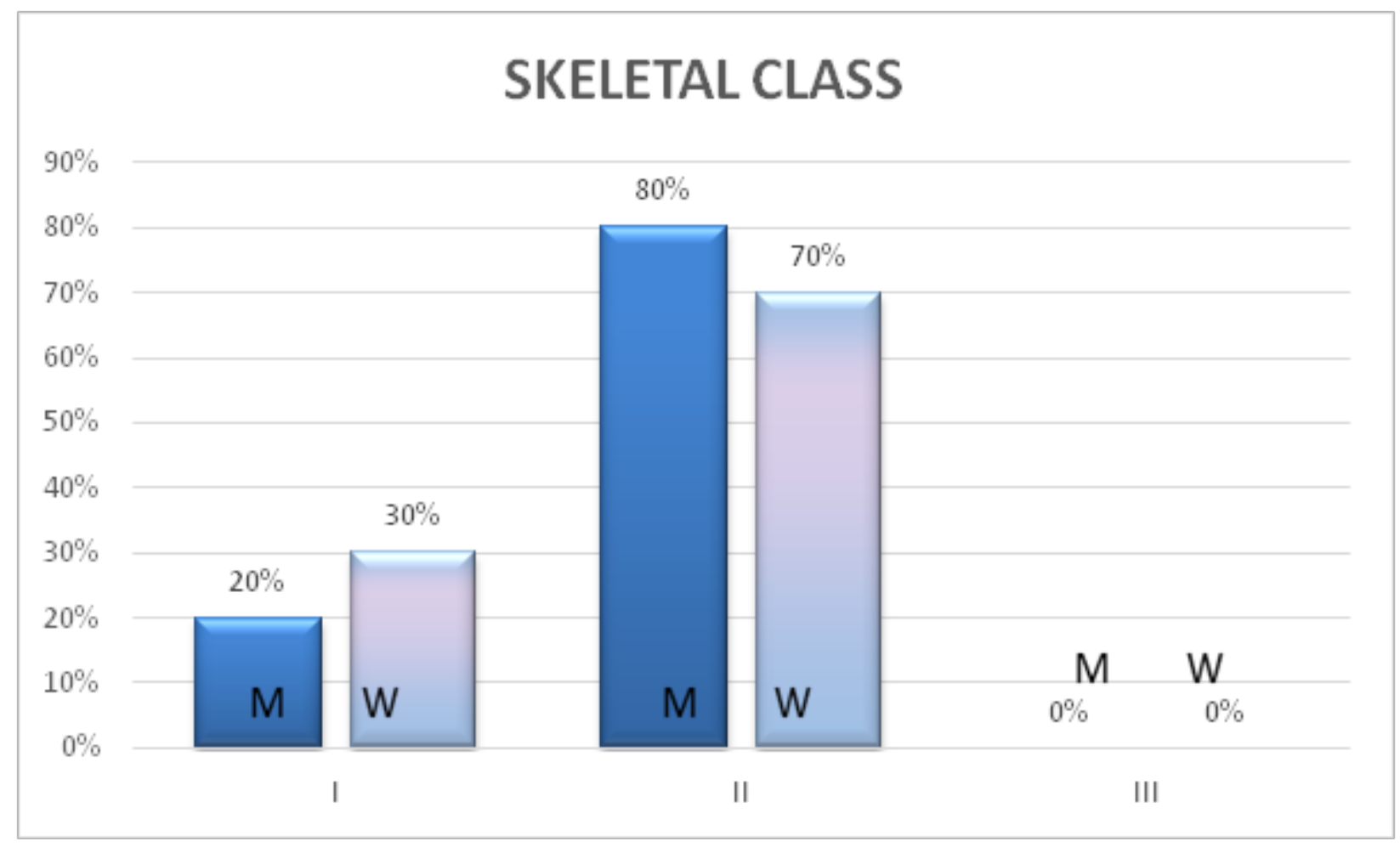

Graph 6 Percentage of skeletal class women and men.

\section{SPRADLEY PG.}

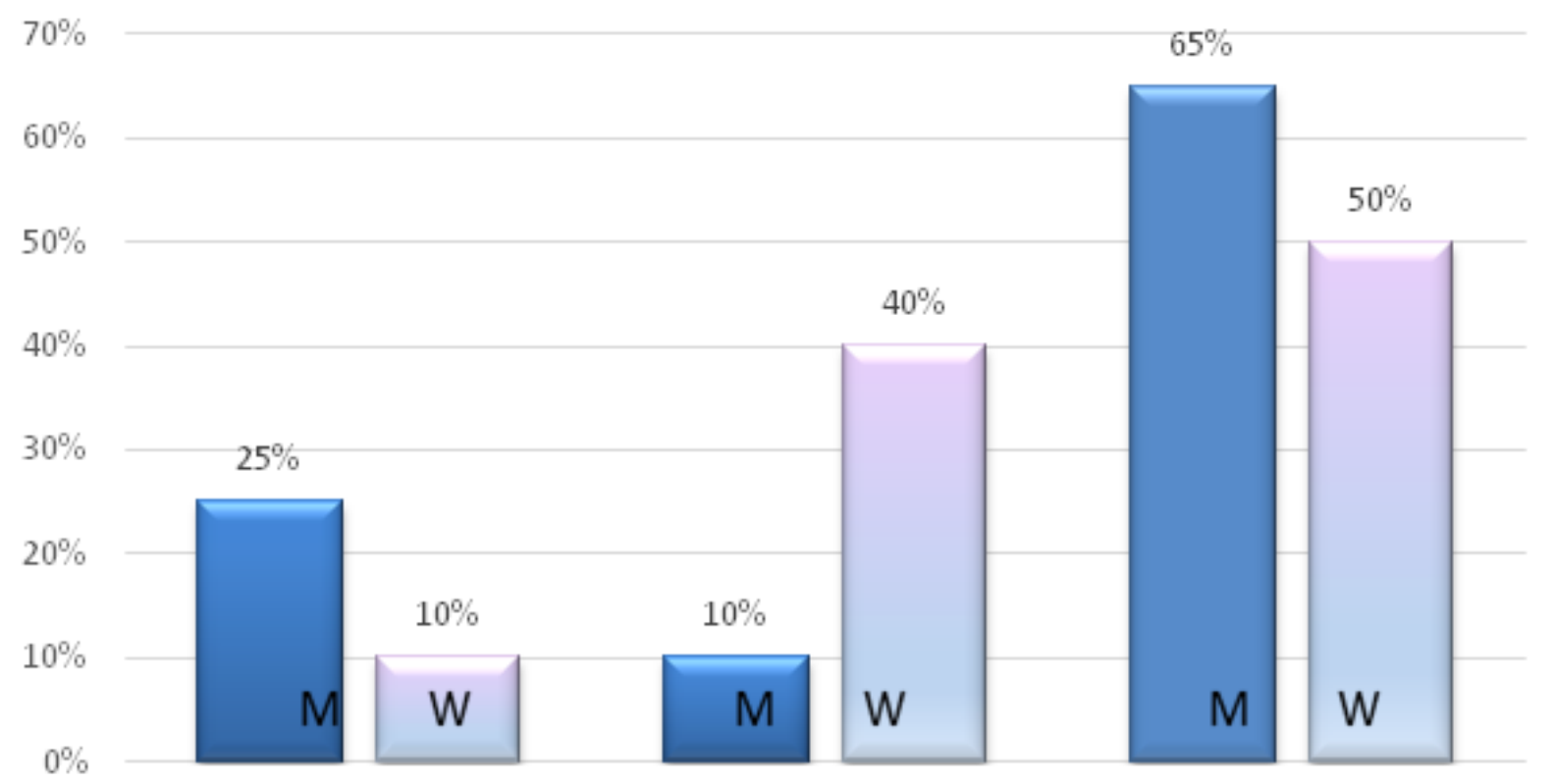

Graph 7 Percentage of relation of Spradley PG-Pg. 


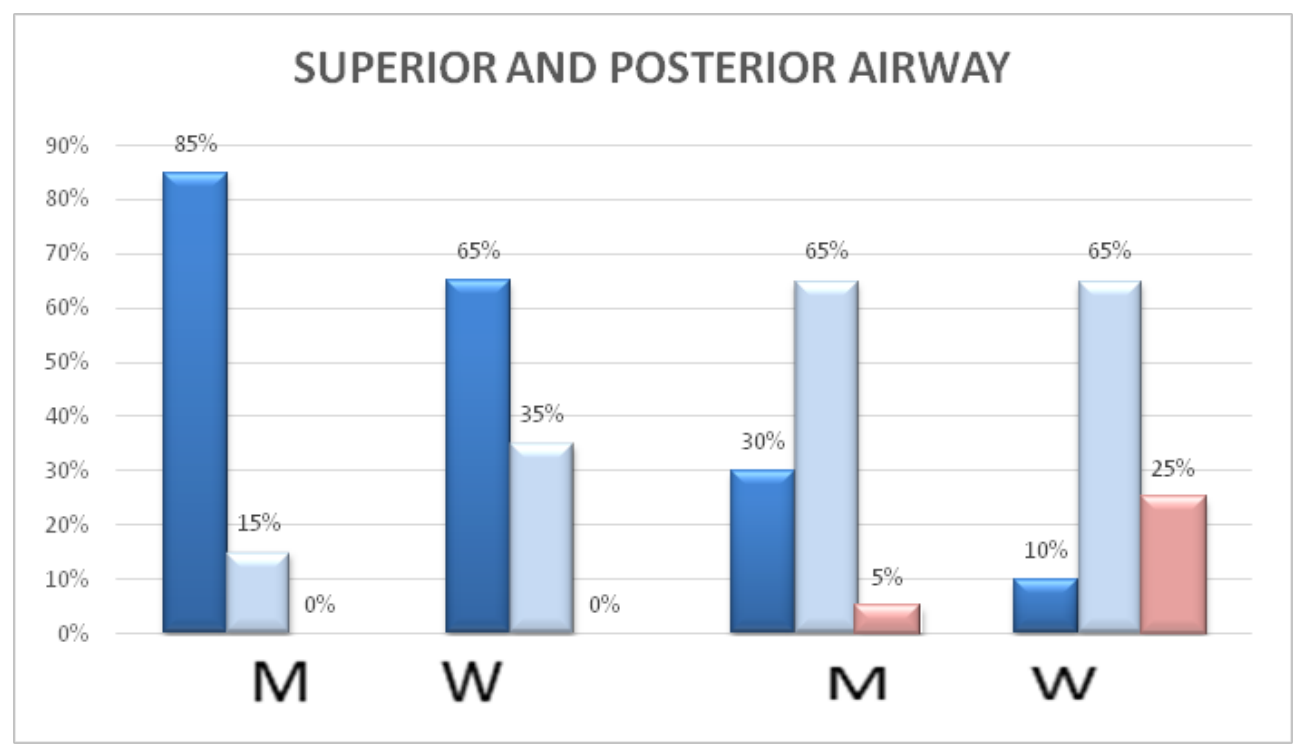

Graph 8 Posterior and superior diameter airway women and men.

\section{Discussion}

The high suspicion of OSA was identified in students attending the Faculty of Dentistry of Río Blanco Ver., In the period February-July 2018 through the Epworth Test. Of the 40 participants who obtained a positive result in this test, $57 \%$ of men and $43 \%$ of women were positive to the diagnosis of OSA according to the value obtained in the measurement of the VAS for each gender.

It was found that most of the patient's positive for the diagnosis of OSA presented skeletal class II, which favors the mandibular retrognathism and therefore a significant reduction of the VAS. These results are similar to those obtained by Banabilh et al., In which they indicated that the most frequent findings in the OSA groups compared to the control group were convex profiles $(71.7 \%)$ and class II malocclusion $(51,7 \%)$, showing that there is a significant difference. This allows determining if there is a direct relationship between class II patients and the diagnosis of OSA. ${ }^{12}$

On the other hand, the mandibular length that plays an important role in mandibular positioning was found to be diminished in both men and women who were positive according to the test and cephalometry. In a study conducted in 2007 by Tsai et al., They found the presence of decreased mandibular length in patients with OSA. In our study, the diminished mandibular length is significantly associated with the high suspicion of OSA and this may be due to the fact that the mandibular position directly affects the spaces of the airway increasing the risk of OSA. ${ }^{11,13}$

It is relevant to mention that the present investigation was carried out in students who presented a high suspicion in sleep disorders within which the OSA is included, by means of the Epworth Test and later said diagnosis is confirmed with the cephalometry, useful tool for the diagnosis of this entity, considered a serious public health problem. Most studies in this area involve evidence of high suspicion of OSA without a polysomnographic diagnosis. In our CórdobaOrizaba region, there are no previous studies reporting craniofacial features comparing adults with and without apnea diagnosed by polysomnography. ${ }^{13}$

A similar correlation has been reported by Ryu et al. Through cephalometric and PSG studies that showed that people with OSA had mandibular retrognathism. Mandibular retrusion is often in individuals with class II malocclusion and the position of the jaw in these people can obstruct the pharynx during sleep, increasing the chances of developing OSA. ${ }^{14,15}$ PSG is an effective test to diagnose OSA, however the origin of airway obstructions that produce OSA cannot be identified by PSG, so the lateral cranial radiograph is a useful tool available to the Dental Surgeon to evaluate respiratory obstructions associated with OSA, which will allow a timely diagnosis and thus contribute to the patient's physical and social well-being.

It is necessary to perform a study similar to that presented by expanding the sample since there is a high prevalence of OSA in young male patients and thus determine the craniofacial phenotypic characteristics that contribute to the development of OSA. ${ }^{16,17}$

\section{Conclusion}

The Epworth test showed significant importance as part of the diagnosis of OSA. Cephalometry is a useful tool to determine the values that indicate a high suspicion of OSA and which in turn confirms the presence or not of it. It was found that Class II Skeletal, Mandibular Retrusion, Spradley line in relation to Pogonion, and the upper airway are directly related to the reduction of the VAS, which will trigger an important problem such as the OSA.

\section{Funding details}

We want to thank PRODEP UV-EXB-555 AND PRODEP CAUV-465 for the funding and support.

\section{Acknowledgments}

Acknowledgments to Dr. Joaquin Romero Ricavar for the support. 


\section{Conflict of interest}

The authors declare that there is no conflict of interest.

\section{References}

1. Pedrosa RP, Drager LF, Gonzaga CC, et al. Obstructive sleep apnea: the most common secondary cause of hypertension associated with resistant hypertension. Hypertension. 2011;58(5):811-817.

2. Omelchenko N, DeVon HA. Obstructive sleep apnea and ischemic stroke. A murky but menacing connection. Adv Nurse Pract. 2008;16(4):65-68.

3. Parra O, Arboix A. Early treatment of obstructive apnea and stroke outcome. Sleep. 2012;35(6)747.

4. Patidar AB, Andrews GR, Seth S. Prevalence of obstructive sleep apnea, associated risk factors, and quality of life among Indian congestive heart failure patients: a cross-sectional survey. J Cardiovasc Nurs. 2011;26(6):452-459.

5. Borges PdTM, da Silva BB, Moita Neto JM, et al. Cephalometric and anthropometric data of obstructive apnea in different age groups. Braz $J$ Otorhinolaryngol. 2015;81(1):79-84.

6. Broström A, Fridlund B, Ulander M, et al. A mixed method evaluation of a group-based educational programme for CPAP use in patients with obstructive sleep apnea. J Eval Clin Pract. 2013;19:173-184.

7. Chami HA, Baldwin CM, Silverman A, et al. Sleepiness, quality of life, and sleep maintenance in REM versus non-REM sleep-disordered breathing. Am J Respir Crit Care Med. 2010;181(9):997-1002.

8. Ciccone A, Proserpio P, Roccatagliata DV, et al. Wake-up stroke and TIA due to paradoxical embolism during long obstructive sleep apnoeas: a cross-sectional study. BMJ. 2013;68(1):97-104.
9. Coughlin SR, Mawdsley L, Mugarza JA, et al. Cardiovascular and metabolic effects of CPAP in obese males with OSA. Eur Respir J. 2007;29(4):720-727.

10. Diaferia G, Badke L, Santos-Silva R, et al. Effect of speech therapy as adjunct treatment to continuous positive airway pressure on the quality of life of patients with obstructive sleep apnea. Sleep Med. 2013;14(7):628635 .

11. Dong JY, Zhang YH, Qin LQ. Obstructive sleep apnea and cardiovascular risk: meta-analysis of prospective cohort studies. Atherosclerosis. 2013;22(9):489-495.

12. Bagai K. Obstructive sleep apnea, stroke, and cardiovascular diseases. Neurologist. 2010;1(6):329-339.

13. Au CT, Chan KCC, Liu KH, et al. Potential Anatomic Markers of Obstructive Sleep Apnea in Prepubertal Children. J Clin Sleep Med. 2018;14(12):1979-1986.

14. Sakakibara M, Yamada S, Kamiya K, et al. Sleep-disordered breathing is an independent risk factor of aborted sudden cardiac arrest in patients with coronary artery spasm. Circ J. 2012;76(9):2204-2210.

15. von Känel R, Natarajan L, Ancoli-Israel S, Mills PJ, Wolfson T, Gamst AC. Effect of continuous positive airway pressure on day/night rhythm of prothrombotic markers in obstructive sleep apnea. Sleep Med. 2013;14(1):58-65.

16. Yurtlu S, Sariman N, Levent E, et al. Short-term positive airway pressure therapy response in obstructive sleep apnea patients: impact of treatment on the quality of life. Tuberk Toraks. 2012;60(4):327-335.

17. Ali LK, Avidan AY. Sleep-disordered breathing and stroke. Rev Neurol Dis. 2008;5(4):191-198. 